\title{
Diagnosis and Management of Clostridium difficile Infection
}

\author{
Tony M. Korman, MBBS, FRACP, FRCPA ${ }^{1}$ \\ ${ }^{1}$ Monash Infectious Diseases, Monash Health, Monash University, \\ Clayton, Victoria, Australia
}

Semin Respir Crit Care Med 2015;36:31-43.

\begin{abstract}
Address for correspondence Tony M. Korman, MBBS, FRACP, FRCPA, Monash Infectious Diseases, Monash Health, Monash University, Clayton, Victoria, Australia (e-mail: tony.korman@monash.edu).
\end{abstract}

\begin{abstract}
Keywords

- Clostridium difficile

- antibiotic-associated colitis

- pseudomembranous colitis

- fecal microbiota transplantation

- fidaxomicin

- toxic megacolcon

There have been dramatic changes in the epidemiology of Clostridium difficile infection (CDI), with increases in incidence and severity of disease, attributed to the emergence of a fluoroquinolone-resistant "hypervirulent" strain, ribotype 027 . C. difficile is now the most common pathogen causing hospital-acquired infection in U.S. hospitals, and community-acquired infections are increasing. The diagnosis of CDI is based on a combination of signs and symptoms, confirmed by laboratory tests. Clinical manifestations of $\mathrm{CDI}$ can range from asymptomatic colonization to severe pseudomembranous colitis and death. Many aspects of laboratory diagnosis of CDI remain contentious. Toxin enzyme immunoassays are too insensitive to be used alone, while nucleic acid amplification tests have emerged as an option, either as a stand-alone test or as part of a multitest algorithm. Oral vancomycin and metronidazole have been the recommended antimicrobial therapy options, and fidaxomicin is an effective new alternative. There is ongoing concern regarding the potential inferiority of metronidazole, in particular for severe CDI. Management of severe CDI and recurrent CDI continue to represent major treatment challenges. Biological therapies for the restoration of the intestinal microbiota (e.g., fecal microbiota transplantation) and monoclonal antibody therapy are promising approaches for CDI management, in particular troublesome recurrent $\mathrm{CDI}$. This review will concentrate on the diagnosis and management of $\mathrm{CDI}$ in adults.
\end{abstract}

Clostridium difficile is a spore-forming anaerobic gram-positive bacillus. The $C$. difficile toxin pathogenicity locus (PaLoc) contains the toxin genes $t c d A$ (encoding toxin $A$ ) and $t c d B$ (toxin $\mathrm{B}$ ) along with three accessory genes: $t c d C$, $t c d R$, and $t c d E$. The roles of the individual toxins in pathogenesis continue to be elucidated, ${ }^{1}$ with evidence demonstrating the virulence of toxin $\mathrm{B}^{2-4}$ toxin $\mathrm{A},{ }^{3,4}$ and possibly binary toxin $(\mathrm{CDT}){ }^{4}$

There have been dramatic changes in the epidemiology of $\mathrm{CDI}$, which is now recognized as a global public health problem. ${ }^{5}$ In the early 2000s, reports emerged from North America and Europe of increases in severe CDI with high mortality rate, particularly in the elderly, associated with increased use of fluoroquinolone antibiotics. ${ }^{6,7}$ The epidemic "hypervirulent" strain was identified as a previously uncommon strain of $C$. difficile (known by various typing methods as toxinotype III, restriction endonuclease analysis type B1, North American pulsed-field type 1, or polymerase chain reaction [PCR] ribotype 027), which was fluoroquinolone resistant, and contained binary toxin and an 18-base pair deletion in $t c d C$, a putative negative regulator of toxin genes, ${ }^{8-10}$ with possible hyperproduction of toxins A and B. ${ }^{9}$

C. difficile is now the most common pathogen causing hospital-acquired infection in U.S. hospitals. ${ }^{11,12}$ The CDC estimates that 250,000 people require hospital care and at least 14,000 people die from CDI each year in the United States. ${ }^{13}$ Almost half of infections occur in people younger than 65 , but more than $90 \%$ of deaths occur in people 65 and
Issue Theme Antimicrobial Resistance: Management of Superbugs; Guest Editor, David L. Paterson, MBBS, PhD, FRACP, FRCPA
Copyright $\odot 2015$ by Thieme Medical Publishers, Inc., 333 Seventh Avenue, New York, NY 10001, USA. Tel: +1(212) 584-4662.
DOI http://dx.doi.org/ 10.1055/s-0034-1398741. ISSN 1069-3424. 
older. Deaths related to CDI increased $400 \%$ between 2000 and 2007. CDI is associated with at least $\$ 1$ billion in excess medical costs per year. ${ }^{14}$ In addition, community-acquired CDI is increasing, and these patients may not have the traditional risk factors for CDI. ${ }^{5,15-19}$

Antibiotics are the major risk factor for the development of healthcare-associated ${ }^{20}$ and community-associated CDI, ${ }^{21,22}$ due to disruption of endogenous intestinal microbiota which promotes $C$ difficile spore germination, vegetative growth, and toxin production. ${ }^{23}$ Meta-analyses identify clindamycin, cephalosporins, and fluoroquinolones ${ }^{20-22}$ as the highest risk antibiotics. The highest risk for CDI is during treatment and in the first month after antibiotic use, but risk continues for up to 90 days. ${ }^{24}$ Proton pump inhibitors also increase the incidence of CDI. ${ }^{25}$

Strategies to prevent CDI in acute care hospitals include early detection and isolation with contact precautions, hand hygiene, environmental cleaning, and antibiotic stewardship. ${ }^{26,27}$ Patients with suspected or proven CDI should be placed under contact precautions, including assignment to a single room with dedicated toileting facilities or cohorting with other infected patients. Gloves and gowns should be worn by all health care personnel upon room entry. Hand washing with soap and water is more effective for physical removal of $C$. difficile spores than alcohol-based hand hygiene products. $^{28}$ Hand washing with soap and water has been recommended when caring for CDI patients, in particular in the setting of a $C$. difficile outbreak. However, contamination of hands is less common when gloves are worn for the patient encounter, ${ }^{29}$ and several studies have not found an increase in CDI with alcohol-based hand hygiene products. ${ }^{27}$

The contaminated hospital surface environment plays a key role in the transmission of $C$. difficile. ${ }^{30} C$. difficile spores can survive on dry surfaces for up to several months and resist killing by standard disinfectants. A C. difficile sporicidal disinfectant $^{31}$ should be used for disinfection of patient rooms and bathrooms. Dedicated medical equipment should be used for patients with CDI whenever possible. Equipment that must be shared between patients should be cleaned and disinfected with a sporicidal agent between uses. Encouraging appropriate use of antimicrobials is recommended, and a meta-analysis concluded that restrictive antibiotic stewardship programs effectively decrease the incidence of $\mathrm{CDI} .{ }^{32}$

In England, the incidence of CDI and related mortality has been reduced markedly ( $>60 \%$ ) coincident with a decrease in ribotype 027 (55-21\% cases) following the introduction of a $C$. difficile control program including strain typing, antimicrobial stewardship (with reduced use of cephalosporins and fluoroquinolones), mandatory reporting, and reduction targets. ${ }^{33}$

\section{Diagnosis of $C$. difficile Infection}

The diagnosis of CDI is based on (1) a combination of signs and symptoms, confirmed by microbiological evidence of $C$. difficile toxin and toxin-producing $C$. difficile in stools, in the absence of another cause, or (2) colonoscopic or histopathological findings demonstrating pseudomembranous colitis $(\mathrm{PMC}){ }^{34}$

\section{Clinical Manifestations}

The clinical manifestations of infection with toxin-producing strains of $C$. difficile range from asymptomatic carriage, to mild or moderate diarrhea, to fulminant and sometimes fatal PMC. $^{35,36}$ The type of disease and severity of disease are related to organism factors ${ }^{37,38}$ and patient risk factors, including the presence of antitoxin antibodies. ${ }^{39}$ Over $20 \%$ of hospitalized adults ${ }^{29,40}$ and up to $50 \%$ of residents of longterm care facilities ${ }^{41}$ may have asymptomatic $C$. difficile carriage and can serve as a reservoir for environmental contamination and sources for $C$. difficile transmission. ${ }^{29,41,42}$ Watery, nonbloody diarrhea, defined as three or more stools per 24-hour period, is the hallmark of symptomatic illness. Mild disease is characterized by diarrhea in the absence of signs and symptoms of colitis. Patients with moderate disease have diarrhea with evidence of colitis characterized by fever and abdominal cramps and discomfort, usually in the lower quadrants. Severe disease is discussed later.

\section{Laboratory Diagnosis}

Many aspects of laboratory diagnosis of CDI remain contentious, including selection of samples, selection of test method(s) and testing algorithms, and clinical validation. ${ }^{43}$ It is important to perform testing for $C$. difficile only on unformed stools, because asymptomatic colonization with C. difficile is not uncommon. ${ }^{44,45}$ In patients with ileus and a strong suspicion for CDI, stool of any consistency, including rectal swabs, can be tested. ${ }^{45}$ All patients with diarrhea who have been hospitalized more than 72 hours should be tested for $C$. difficile, irrespective of the physicians' request, ${ }^{44}$ but testing can also be performed on samples submitted within the first 72 hours of hospitalization. Patients with diarrhea who have been admitted in a health care facility within a period of 3 months before the development of diarrhea should also be tested for $C$. difficile. ${ }^{44} C$. difficile testing should be performed on unformed stool samples of all patients with potential infective diarrhea and negative tests for common enteropathogens, irrespective of age, prior antibiotic use, comorbidity, co-medication, and onset of diarrhea (community or nosocomial). ${ }^{44}$ Repeat testing following a negative test within 7 days is rarely useful, using any test method. ${ }^{46-48}$ Repeat testing during the same episode of diarrhea is not recommended, no diagnostic test should be used as a "test of cure," 49 and C. difficile tests may remain positive for many weeks. ${ }^{46}$

\section{Cell Culture Cytotoxicity Neutralization Assay}

The cell culture cytotoxicity neutralization assay (CCCNA) has historically been considered to be the gold standard for diagnosis of $\mathrm{CDI}^{50}$ However, CCCNA has 75 to $85 \%$ lower sensitivity than toxigenic culture, ${ }^{51}$ a long turnaround time (24-48 hours), requires cell culture expertise, and is now seldom used as a routine diagnostic test. ${ }^{43}$

\section{Toxigenic Culture}

Toxigenic culture comprises isolation of $C$. difficile from feces followed by confirmation of toxin production by the isolate. Toxigenic culture is labor intensive, has a long turnaround time ( $>48$ hours), and is not practical for routine diagnostic 
use. In addition, toxigenic culture detects the ability of a C. difficile strain to produce toxin in vitro and does not necessarily indicate in vivo production of toxin in the host. Toxigenic culture is now considered by many to be the gold standard for $C$. difficile detection. ${ }^{50}$ The 2010 Society of Healthcare Epidemiology of America (SHEA)/Infectious Disease Society of America (IDSA) guidelines support the use of toxigenic culture as the gold standard in method comparison studies. ${ }^{49}$ However, although toxigenic culture may result in more positive specimens, it is not superior to CCCNA for the diagnosis of clinical disease. ${ }^{43,50} \mathrm{C}$. difficile culture is also important to allow for strain typing in the setting of an outbreak or other epidemiological studies, for antimicrobial susceptibility testing for surveillance of antimicrobial resistance, for new test method evaluation, and to evaluate new therapies. $^{52}$

\section{Toxin Enzyme Immunoassays}

Enzyme immunoassays (EIAs) for detection of $C$. difficile toxins $A$ and $B$ are rapid, inexpensive tests which are simple to perform, and were widely adopted by many laboratories. Toxin EIAs have high specificity (>95\%), but have unacceptably low sensitivity compared with CCCNA (67-83\%) ${ }^{44,53}$ and toxigenic culture (45-66\%), ${ }^{44,53}$ and are no longer recommended for use as stand-alone tests for CDI diagnosis. ${ }^{43,49}$

\section{Glutamate Dehydrogenase}

Glutamate dehydrogenase (GDH) ("common antigen") is produced by all $C$. difficile isolates (including both toxigenic and nontoxigenic strains). ${ }^{54,55}$ A meta-analysis confirms that GDH has high sensitivity (>90\% vs. CCCNA assay, $>80 \%$ vs. toxigenic culture), low false-positive rate $(<2 \%)$, and high negative predictive value (NPV). ${ }^{56}$ In a recent UK study of $>12,000$ specimens, GDH sensitivity was very high (96\% vs. CCCNA, 95\% vs. toxigenic culture). ${ }^{53} \mathrm{GDH}$ is a convenient, rapid, inexpensive test with a rapid turnaround time which can be used as a screening test. ${ }^{46,51,57}$ Positive GDH tests must be followed up with a confirmatory test, such as a toxin EIA or a molecular test for detection of toxin genes. ${ }^{43}$

\section{Nucleic Acid Amplification Tests}

Nucleic acid amplification tests (e.g., PCR) for $C$. difficile usually detect toxin genes (e.g., $t c d B$ which encodes toxin B). Some assays also detect other targets (e.g., binary toxin genes, $t c d C$ deletion) which act as surrogate markers for presumptive identification of ribotype 027 strains, but can also detect other ribotypes. ${ }^{58,59}$ NAATs are rapid tests with high specificity (>95\%), high sensitivity for $C$. difficile detection (>90\% vs. CCCNA, $>85 \%$ vs. toxigenic culture), and high NPVs. ${ }^{44,60}$ The use of NAAT as a stand-alone test for $C$. difficile has been advocated, ${ }^{61,62}$ while others suggest NAAT should be used as part of a multistep algorithm. ${ }^{43,61}$

Key questions regarding the clinical utility of NAATs remain, particularly regarding specificity and positive predictive value (PPV). ${ }^{43}$ NAATs can identify $C$. difficile isolates that harbor toxin genes which are not expressed. A positive C. difficile NAAT assay does not differentiate between active infection and asymptomatic carriage. To reduce possible false positives, it is important to only test unformed feces from patients who have suspected CDI. Introduction of NAAT assays to replace toxin EIA or CCCNA testing is associated with a $>50 \%$ increase in CDI incidence, ${ }^{63}$ and CDI surveillance requires adjustment for testing methods. ${ }^{64,65}$ Rapid NAAT assays may enable earlier diagnosis of CDI and avoiding the costs of repeat testing. ${ }^{66}$ NAAT are more expensive than toxin EIAs; however, the cost of some rapid NAATs may be favorable compared with other options (e.g., a GDH/CCCNA algorithm) when labor costs are considered. ${ }^{67}$ Further studies are required to assess the overall cost-effectiveness of NAATs for C. difficile detection. ${ }^{43}$

\section{Testing Algorithm Approaches}

Testing algorithm approaches have been used for $C$. difficile laboratory diagnosis. In one two-step algorithm, the GDH assay is used as a screening test, and if negative, the specimen can be rapidly reported as negative without additional testing. If the specimen is GDH positive, confirmatory testing (e.g., NAAT) can be performed, and reported as positive or negative. ${ }^{43,44}$ In a three-step algorithm, samples are tested for GDH, and if positive, they are tested by using a toxin EIA. Toxin-positive samples can be reported as positive, but GDH-positive/toxin-negative samples are then tested by using NAAT. Alternatively, the samples can be screened by using a GDH/toxin combination EIA, but as the toxin EIA component has low sensitivity, samples with discrepant results (i.e., GDH positive/toxin negative) should be tested using NAAT. ${ }^{43}$

The 2010 SHEA/IDSA guidelines included an interim recommendation to use GDH as an initial screening test and then CCCNA or toxigenic culture as the confirmatory test for GDH-positive stool specimens only. ${ }^{49}$ The 2009 European guidelines recommended two- or three-stage algorithms. One option was to use GDH or NAAT as an initial screen, and samples with a negative test result can be reported as negative. Samples with a positive test should then be tested for toxin, and if positive, CDI is confirmed. If the toxin test is negative, but GDH or NAAT is positive, CDI cannot be differentiated from asymptomatic colonization. $^{44}$

Multistage algorithms performed better than standalone assays in a large UK study. GDH/EIA had high specificity (>99\%) and PPV (>90\%), while GDH/PCR had high sensitivity (>90\%) and specificity (>95\%) but a lower PPV (81\% vs. toxigenic culture, $60 \%$ vs. CCCNA). ${ }^{53}$ The UK algorithm recommends NAAT or a GDH assay to screen for the presence of C. difficile, followed by a toxin test (e.g., EIA) to confirm the diagnosis. The initial screening test using NAAT and GDH have high NPVs and can rapidly exclude CDI. ${ }^{53}$ However, this approach can rely on a "confirmatory" toxin EIA second step which may have unacceptably low sensitivity, and has not been accepted in the United States. ${ }^{43}$

\section{Clinical Validation of Laboratory Diagnosis}

A large prospective multicenter UK study provides important clinical validation of the laboratory diagnosis of $C$. difficile infection. Multiple tests for $C$. difficile were performed on 
more than 12,000 unformed fecal samples, and corresponding outcome data for more than 6,500 inpatient episodes was analyzed. Mortality was significantly higher in patients with positive CCCNA test and toxigenic culture (16.6\%), compared with those with positive toxigenic culture alone (9.7\%), whose mortality was similar with negative toxigenic culture (8.6\%). These findings confirm that CCCNA may be the best indicator of disease, but as it lacks sensitivity compared with toxigenic culture, it is no longer recommended as a stand-alone test. ${ }^{61}$ A new diagnostic category of "potential C. difficile excretor" was proposed for patients who were toxigenic culture positive, but CCCNA negative, to characterize patients with diarrhea which may not be due to $\mathrm{CDI}$, but who can cause crossinfection. ${ }^{53}$

\section{Endoscopy}

PMC is diagnosed by direct visualization of pseudomembranes on lower gastrointestinal endoscopy (either sigmoidoscopy or colonoscopy) or by histopathologic examination. PMC may spare the rectum in approximately $10 \%$ of patients, so colonoscopy is preferred. ${ }^{68-71}$ Pseudomembranes appear as tightly adherent, raised yellow or offwhite plaques up to $2 \mathrm{~cm}$ in diameter, which may be covered with mucus, often with intervening normal looking colonic mucosa. ${ }^{72}$ Histopathological findings include the typical "summit" or "volcano" lesion with an erupting "pseudomembrane" of inflammatory cell infiltrate and debris with focal mucosal necrosis. ${ }^{72,73}$ PMC is highly specific for $\mathrm{CDI},{ }^{35,72}$ but pseudomembranes are detected only in half of CDI cases with positive CCCNA. ${ }^{49,74}$ Endoscopy rarely identifies pseudomembranes in CDI in patients with underlying inflammatory bowel disease. ${ }^{75,76}$ Other endoscopic findings may include bowel wall edema, erythema, friability, and inflammation. There is a risk of perforation with endoscopy in cases of fulminant colitis. ${ }^{77}$ Endoscopy techniques may also be utilized for delivery of donor feces infusion (see later).

\section{Diagnostic Imaging}

Plain abdominal radiography can demonstrate polypoid mucosal thickening, "thumbprinting" (wide transverse bands associated with haustral fold thickening), or gaseous distention of the colon. Toxic megacolon is suggested by acute dilatation of transverse colon to a diameter $>6 \mathrm{~cm}$ associated with systemic toxicity and the absence of mechanical obstruction. ${ }^{78}$ Abdominal CT scan findings include wall thickening, low-attenuation colonic mural thickening corresponding to mucosal and submucosal edema ("target" or "double halo" sign), trapping of oral contrast material with high attenuation in the colonic lumen alternating with thickened inflamed mucosa with low attenuation ("accordion" sign), wall thickening involving the entire colon (pancolitis), pericolonic fat stranding, and ascites. Abdominal CT scan findings (colonic wall thickness $>15 \mathrm{~mm}$, pleural effusion) may be independent predictors of complicated CDI in addition to clinical and laboratory parameters. ${ }^{79}$ However, radiographic findings are neither sensitive nor specific for CDI. ${ }^{77,79-83}$

\section{Management of $C$. difficile Infection}

\section{General Principles}

Stopping the inducing antibiotic(s) as soon as possible is strongly recommended for $\mathrm{CDI} .{ }^{49}$ Patients who continue concomitant antimicrobial therapy are more difficult to treat successfully and have a higher CDI relapse rate. ${ }^{84,85}$ Up to $20 \%$ of CDI cases may resolve without antimicrobial therapy. ${ }^{86}$ Supportive care should include careful fluid and electrolyte management. The use of antimotility agents for CDI treatment has traditionally been discouraged, ${ }^{34,49}$ but evidence that they worsen outcome is lacking. ${ }^{87}$

\section{Antimicrobial Therapy}

\section{Metronidazole and Vancomycin}

The recommended treatment options for initial non-severe CDI are oral metronidazole $500 \mathrm{mg}$ three times daily or oral vancomycin $125 \mathrm{mg}$ four times daily for 10 days. ${ }^{34,49} \mathrm{Fi}-$ daxomicin $200 \mathrm{mg}$ twice daily (see later) is another potential option. ${ }^{88}$ In prospective trials, the mean time for diarrhea resolution is 3 to 4 days. ${ }^{89}$ Failure to respond to metronidazole therapy within 5 to 7 days could prompt consideration of a change in therapy to vancomycin at standard dosing. ${ }^{62}$

Systematic reviews have concluded that no antimicrobial agent studied has proven to be clearly superior for the initial cure of CDI. ${ }^{90,91}$ Metronidazole has been recommended as first-line treatment for mild/moderate disease due to low cost and possibly reduced risk of vancomycin-resistant enterococci (VRE) ${ }^{34,49}$ However, due to ongoing concern regarding potential inferiority compared with vancomycin, ${ }^{89,92}$ recommendations now often relegate metronidazole to treatment of mild disease only. ${ }^{93,94}$

Following the emergence of ribotype 027, increased risk of treatment failure and recurrences after metronidazole therapy were recognized, ${ }^{36,95-97}$ in particular in patients with severe disease, ${ }^{98}$ and with continuation of antibiotics. ${ }^{99}$ Other evidence for inferiority of metronidazole compared with vancomycin include more rapid resolution of symptoms, ${ }^{97,100}$ and reduction of $C$. difficile stool levels. ${ }^{97}$ Analysis of data from trials of the ineffective toxin-binder tolevamer demonstrated that the efficacy of metronidazole was inferior to vancomycin ( 73 vs. $81 \%$ overall, 66 vs. $79 \%$ for severe CDI). ${ }^{101}$

The reason for the poor performance of metronidazole is not well understood, ${ }^{34,89}$ but comparing the pharmacokinetic properties to vancomycin may provide some explanation. ${ }^{34,92,93}$ Oral metronidazole is almost completely absorbed in the upper gastrointestinal tract, but bactericidal fecal concentrations $(>9 \mu \mathrm{g} / \mathrm{g}$ ) are attained in acute CDI. Fecal concentrations decrease during recovery, with significantly lower concentrations in formed compared with semiformed or watery stools. ${ }^{102}$ In contrast, oral vancomycin maintains high stool concentrations $(>3,000 \mu \mathrm{g} / \mathrm{g})$ throughout the course of CDI therapy. ${ }^{102,103}$ Metronidazole resistance has not been recognized as a cause of treatment failure. ${ }^{34,92}$ However, $C$. difficile strains with reduced susceptibility to 
metronidazole have been identified, ${ }^{104}$ while vancomycin resistance is extremely rare. ${ }^{92,105}$

\section{Fidaxomicin}

Fidaxomicin is a promising alternative therapy for CDI. Oral fidaxomicin attains high fecal concentrations with minimal plasma concentrations. ${ }^{106}$ The safety profile of fidaxomicin is comparable to oral vancomycin. ${ }^{107}$ Two large double-blind randomized controlled trials (RCTs) (total $n=572$ received fidaxomicin) confirmed noninferiority to vancomycin for clinical cure rates. ${ }^{108-110}$ In patients taking concomitant antibiotics, fidaxomicin was significantly more effective than vancomycin in achieving clinical cure. ${ }^{85,109}$

Treatment with fidaxomicin was associated with a significantly lower rate of recurrence than vancomycin in the 4 weeks after completion of treatment in both studies (15 vs. $25 \%{ }^{28}$ and 13 vs. $27 \%^{29}$ ). Recurrence rates were higher among ribotype 027 than among non-ribotype 027 cases, and were not significantly different following treatment with vancomycin or fidaxomicin. ${ }^{111}$ There may be a potential role for fidaxomicin in first-line CDI treatment for patients "with risk factors known to portend relapse and severe infection." 88 Possible explanations for reduced recurrence rates include superior inhibition of $C$. difficile toxin production ${ }^{112}$ and spore production, ${ }^{113}$ and better preservation of the intestinal microbiome during and after treatment of CDI. ${ }^{114-116}$ Wholegenome sequencing demonstrated that fidaxomicin was superior to vancomycin for preventing both $C$. difficile reinfection and relapse. ${ }^{117}$ Fidaxomicin was also significantly less likely than vancomycin to promote acquisition of VRE (7 vs. $31 \%$ ) and Candida species (19 vs. $29 \%$ ) colonization. ${ }^{118}$ A key issue to be resolved is the comparative cost-effectiveness of fidaxomicin. ${ }^{119,120}$

\section{Other Oral Antimicrobial Agents}

Nitazoxanide may be as effective as vancomycin for CDI, although a small RCT (only $n=23$ received nitazoxanide) was unable to confirm noninferiority. ${ }^{121}$ Many new drugs are in preclinical and clinical development, including Phase III clinical trials with cadazolid and surotomycin. ${ }^{94,122}$

\section{Severe Disease}

Patients with severe disease may develop a colonic ileus or toxic dilatation and present with abdominal pain and distension but with minimal or no diarrhea. Complications of severe C. difficile colitis include dehydration, electrolyte disturbances, hypoalbuminemia, toxic megacolon, bowel perforation, hypotension, renal failure, systemic inflammatory response syndrome, sepsis, and death. ${ }^{49}$

Management guidelines and treatment studies have proposed various definitions of severe/and or complicated CDI and use different severity criteria, which has important implications for comparison of treatment outcomes. ${ }^{92}$ The SHEA/IDSA CDI treatment guidelines use the criteria leucocyte count $>15 \times 10^{9} / \mathrm{L}$, rise in serum creatinine $(>1.5$ times the premorbid level), hypotension, shock, ileus, or toxic megacolon to define severe/complicated $\mathrm{CDI} .{ }^{49}$
Other U.S. guidelines classify severe CDI with serum albumin $<30 \mathrm{~g} / \mathrm{L}$ plus one of leukocytosis or abdominal tenderness, and complicated CDI with one of a list of other clinical and laboratory criteria. ${ }^{62}$ The European guidelines define severe CDI as an episode of CDI with (one or more specific signs and symptoms of) severe colitis and/or one or more unfavourable prognostic factors (leucocytosis, albumin $<30 \mathrm{~g} / \mathrm{L}$ or rise in serum creatinine) or a complicated course of disease, with significant systemic toxin effects and shock, resulting in need for ICU admission, colectomy or death. A systematic review found that the most common risk factors for complicated CDI were older age, leucocytosis, renal failure, and comorbidities. ${ }^{123}$ Leukocyte count $>20 \times 10^{9} / \mathrm{L}$ and serum creatinine level $>133 \mu \mathrm{mol} / \mathrm{L}$ $(>1.5 \mathrm{mg} / \mathrm{dL}$ ) measured on the day of diagnosis were predictors of a complicated course of CDI in the fidaxomicin RCTs. ${ }^{124}$

Several clinical prediction rules (CPRs) for adverse outcomes of CDI have been developed. A scoring system devised retrospectively to identify patients with severe infection in one RCT used the presence of PMC, treatment in an ICU, or two out of four parameters (age $>60$ years, $\mathrm{T}>38.3^{\circ} \mathrm{C}$, albumin $\left.<2.5 / \mathrm{dL}, \mathrm{WBC}>15 \times 10^{9} / \mathrm{L}\right) .{ }^{98}$ A combination of five clinical and laboratory variables measured at the time of CDI diagnosis (the ATLAS score: age, treatment with systemic antibiotics, leukocyte count, albumin, and serum creatinine) predicted treatment response to CDI therapy in the fidaxomicin RCTs and may be useful in stratifying patients. ${ }^{125}$ A systematic review which evaluated the available CPRs demonstrated serious methodological limitations which led to suboptimal quality and debatable utility and recommended the development of evidence-based tools through appropriate prospective cohorts. $^{126}$

\section{Strain Type}

Several studies demonstrated the importance of strain type (e.g., ribotypes 027 and 078) on CDI outcome, ${ }^{127-129}$ while some studies did not. ${ }^{130}$ Recent large studies confirm that $C$. difficile genotype (including ribotypes 027 and 078) predicts severe disease and mortality, $37,38,131$ and new virulent strains associated with severe disease continue to emerge. $59,127,132$

\section{Oral Antibiotic Therapy}

There are no RCTs available to guide recommendations for the choice and dosing of antibiotic therapy for the treatment of patients with severe CDI. Oral vancomycin $125 \mathrm{mg}$ four times daily is recommended as the preferred therapy for severe or refractory CDI. ${ }^{34,49}$ Although levels achieved may be equivalent to standard dose, ${ }^{133}$ increased vancomycin dose (500 mg four times daily) has been suggested based on expert opinion only. ${ }^{34,49}$ The use of metronidazole alone for severe CDI is now discouraged. ${ }^{34}$ The cure rate was significantly higher with vancomycin than with metronidazole (97 vs. $76 \%$ ) in patients with severe $\mathrm{CDI}(n=69)$ in a RCT post hoc subgroup analysis $^{91,98}$ but not on an intention-to-treat analysis. ${ }^{90,91}$ There are no data available on the efficacy of fidaxomicin in severe $\mathrm{CDI}^{34}$ 


\section{Intravenous Antibiotics}

Patients with severe CDI and ileus may have delayed passage of oral antibiotics into the colon and may benefit from the addition of intravenous metronidazole (500 mg three times daily). Fecal concentrations in the therapeutic range can be achieved due to biliary and intestinal excretion. ${ }^{102,134}$ However, in one small retrospective report, there was no difference in treatment outcomes between oral vancomycin monotherapy and combination therapy with oral vancomycin and metronidazole (mostly intravenous) for severe CDI. ${ }^{135}$ In a nonrandomized study, intravenous metronidazole was inferior to oral metronidazole for $\mathrm{CDI},{ }^{136}$ so oral therapy should be administered whenever feasible. ${ }^{136}$ Intravenous vancomycin is not useful for CDI therapy. ${ }^{137}$

Tigecycline has potent in vitro activity ${ }^{105}$ and suppresses both $C$. difficile toxin production and sporulation. ${ }^{138}$ Tigecycline achieves high stool concentrations with relative sparing of indigenous anaerobic microflora. ${ }^{139,140}$ There are case reports and small case series using intravenous tigecycline as adjunctive or alternative therapy for severe and/or refractory $\mathrm{CDI},{ }^{141-143}$ but prospective clinical trials are lacking.

\section{Intracolonic Vancomycin}

Intracolonic vancomycin (vancomycin enema) may be an effective adjunctive therapy for severe CDI for patients unable to tolerate the oral preparation, or with toxic megacolon or ileus which would prevent oral vancomycin from reaching the colon, but optimal dosing is uncertain. ${ }^{144-146}$

\section{Surgery}

In a systematic review of 31 studies with 1,433 patients, the 30-day mortality was $41 \%$ (range, $19-71 \%$ ), and predictors of postoperative death included preoperative intubation, acute renal failure, multiple organ failure, and shock requiring vasopressors. ${ }^{147}$ Notwithstanding selection bias in retrospective studies, emergency colectomy for patients with fulminant CDI may provide a survival advantage compared with ongoing medical therapy. ${ }^{148,149}$ However, the criteria for surgical intervention, optimal timing, and preferred surgical procedure remain uncertain. ${ }^{150-152}$

Indications for surgical intervention in CDI include colonic perforation, toxic megacolon, and rapidly progressive and/or refractory disease with systemic inflammatory response syndrome leading to multiorgan system failure. ${ }^{153}$ In a retrospective review, colectomy was most beneficial for immunocompetent patients aged $\geq 65$ years with a leucocyte count $\geq 20 \times 10^{9} / \mathrm{L}$ and/or a plasma lactate 2.2 to 4.9 $\mathrm{mmol} / \mathrm{L}^{148}$ Early surgery is usually recommended, before the development of shock and the need for vasopressors, usually 3 to 5 days after diagnosis in patients who are worsening or not clinically improving. ${ }^{152}$ Further investigation is required to evaluate CPRs that can predict deterioration to better inform decision making with regard to surgery timing. ${ }^{152}$

Subtotal colectomy (removal of the colon, with the rectum remaining in situ) with end ileostomy is the currently accepted surgical procedure of choice for fulminant CDI based on low-quality evidence. ${ }^{148,150,152}$ Diverting loop ileostomy and colonic lavage (with polyethylene glycol and vancomycin) may be an alternative to subtotal colectomy. A study of 42 patients reported reduced morbidity compared with historic controls who had colectomy (19 vs. $50 \%$ ) and preservation of the colon in $93 \%$ of patients. ${ }^{154}$ This surgical approach is promising, but further data, ideally from RCTs, are required before this is accepted as standard practice. ${ }^{147,152,155}$

\section{Recurrent C. difficile Infection}

Management of recurrent CDI continues to provide major challenges. In a systematic review of 26 studies, at least one recurrence occurred in $22 \%$ of cases of CDI treated mainly with metronidazole or vancomycin. ${ }^{123}$ After a first recurrence, the risk of further recurrences may be up to $40 \%$, and $>60 \%$ after two or more recurrences. ${ }^{156,157}$ A systematic review found that the most frequent risk factors for recurrence were older age, use of antibiotics after diagnosis, use of proton pump inhibitors, and strain type. ${ }^{123}$ Recurrence usually occurs 3 to 21 days (average 6 days) ${ }^{35}$ after completion of a treatment course.

Recommendations for the first recurrence of CDI are ceasing any causative antibiotic therapy, and treatment with the same options as for the initial episode. ${ }^{49}$ Oral vancomycin is recommended, ${ }^{34}$ and oral metronidazole may be an option for non-severe recurrent $\mathrm{CDI} .{ }^{49}$ The incidence of a second recurrence after treatment of a first recurrence with oral metronidazole or vancomycin is similar. $^{34,101}$ In patients with a first recurrence of CDI, fidaxomicin was similar to vancomycin in achieving an initial clinical response, but the recurrence rate was lower (19 vs. 35\%). ${ }^{158}$

For treatment after multiple recurrences of $\mathrm{CDI}$, a repeat vancomycin course followed by tapering and/or pulse strategy over weeks ${ }^{157,159}$ is recommended ${ }^{34,49}$ without proven efficacy, "in the hope that $C$. difficile vegetative forms will be kept in check while allowing restoration of the normal flora." ${ }^{34}$ Fidaxomicin has been suggested as a "chaser" regimen following vancomycin for patients with recurrent CDI. ${ }^{160}$ Following multiple recurrent $\mathrm{CDI}$, metronidazole is not recommended because of the potential for neurotoxicity. ${ }^{49}$

Rifaximin, an orally nonabsorbed rifamycin, ${ }^{161}$ is a promising option for recurrent $\mathrm{CDI}$, with reports of small uncontrolled case series. ${ }^{162-165}$ In a pilot RCT, patients receiving a rifaximin "chaser" ( $n=33$ ) following standard anti-CDI antibiotics had significantly decreased incidence of recurrent diarrhea compared with placebo. ${ }^{166}$ However, there is concern regarding emerging rifaximin resistance in C. difficile. ${ }^{167-170}$ Biological therapies for recurrent CDI are discussed below.

\section{Biological Therapies}

There is increasing evidence that $\mathrm{CDI}$ is a microbiome-related disease. ${ }^{23}$ Using microbiome data, patients with CDI and nonCDI diarrhea can be distinguished from healthy controls. ${ }^{171}$ Patients with recurrent CDI have decreased diversity of their fecal microbiome. ${ }^{172}$ Restoration of the intestinal microbiota using biological therapies is an attractive approach for CDI management. ${ }^{173}$ 


\section{Nontoxigenic C. difficile Colonization}

Colonization with nontoxigenic $C$. difficile strains is associated with a decreased risk of developing subsequent CDI. ${ }^{174}$ In 1987 , two patients with relapsing CDI responded to administration of a nontoxigenic $C$. difficile strain. ${ }^{175}$ A nontoxigenic $C$. difficile strain (VP20621) was well tolerated and able to colonize the gastrointestinal tract in a Phase I study, ${ }^{176}$ and reduced the incidence of CDI recurrence by at least $50 \%$ compared with placebo in a recent Phase II dose-finding study. ${ }^{177}$

\section{Probiotics}

The role of probiotics for prevention and treatment of CDI remains contentious. ${ }^{173,178}$ Possible mechanisms of action of probiotics such as Saccharomyces boulardii include direct activity against $C$. difficile (inhibition of adherence, ${ }^{179}$ toxin proteolytic digestion ${ }^{180}$ ) and modulation of the host response (inhibition of proinflammatory signaling pathways ${ }^{181}$ and stimulation of specific IgA antitoxin production ${ }^{182}$ ).

The clinical application of probiotics for prevention and/or treatment of CDI has been limited by a lack of data from large well-designed RCTs. ${ }^{173}$ A Cochrane review concluded that there was insufficient evidence to recommend probiotic therapy as an adjunct to antibiotic therapy, and no evidence to support the use of probiotics alone in the treatment of CDI. ${ }^{183}$ Systematic reviews and meta-analyses concluded that there was moderate quality evidence to suggest that probiotics may be both safe and effective for preventing CDI. ${ }^{184,185}$ However, a large double-blind RCT (PLACIDE study ${ }^{186}$ found no evidence that a multistrain probiotic of lactobacilli and bifidobacteria was effective in prevention of CDI or antibiotic-associated diarrhea. ${ }^{187}$

\section{Fecal Microbiota Transplantation (Donor Fecal Infusion)}

Restoration of intestinal dysbiosis by reintroduction of normal flora is the rationale for donor fecal infusion or fecal microbiota transplantation (FMT) for CDI. ${ }^{188-190}$ Numerous small case series ${ }^{191,192}$ and meta-analyses have reported clinical "cure" rates over 90\% following FMT for recurrent CDI. ${ }^{193-196}$ A small ( $n=16$ in treatment group) open-label RCT of duodenal infusion of donor feces for recurrent CDI was terminated early after interim analysis demonstrated benefit (resolution of diarrhea after one infusion 81\% vs. 23-31\% treated with vancomycin). ${ }^{197}$ After receiving donor feces infusion, patients had microbiota diversity resembling the healthy donors. ${ }^{197}$ There are reports of FMT used successfully in patients with severe CDI, ${ }^{198,199}$ and cases series demonstrating efficacy and safety for treatment of CDI in immunocompromised patients. ${ }^{200}$ FMT may represent a cost-effective strategy for treatment of recurrent CDI. ${ }^{201}$

Although FMT shows great promise, many practical, procedural, technical, ethical, safety, and regulatory issues are yet to be fully addressed. Although initially designated as an investigational new drug, the U.S. FDA later provided interim guidance to exercise discretion regarding these requirements, provided that the treating physician obtains adequate informed consent that the use of FMT for CDI is investigational and discusses potential risks. ${ }^{202,203}$
Rigorous donor screening protocols to minimize the risk of transmitted infection have been proposed. ${ }^{192,204}$ A systematic review concluded that FMT using stool from a related donor had a slightly higher cure rate. ${ }^{193}$ Fresh stool (within 8 hours of passage) is usually recommended, but this has not been studied rigorously. ${ }^{188}$ However, excellent results ( $>90 \%$ overall success rate) were reported using a standardized frozen preparation of stool from "universal" donors. ${ }^{188,205,206}$ The optimal route of administration has not been determined. In a systematic review, instillation by gastroscopy, nasogastric tube, or nasojejunal tube was marginally less effective than other methods (e.g., rectal tube/ enema, colonoscopy). ${ }^{193}$ Ideally, large RCTs should be undertaken to confirm the efficacy and define best practices for FMT. ${ }^{193,203}$

\section{Defined Bacteriotherapy}

Defined bacteriotherapy shows promise for the treatment of intestinal dysbiosis associated with recurrent CDI. ${ }^{207,208}$ In 1989 , rectal instillation of a mixture of 10 bacterial strains cured five patients with re-establishment of fecal anaerobic bacteria. ${ }^{209}$ Recently, targeted restoration of the intestinal microbiota with defined bacteriotherapy resolved relapsing CDI in a mouse model. ${ }^{210}$ Colonoscopic delivery of a synthetic "stool substitute" of purified cultures of 33 bacterial species derived from a single healthy donor cured two patients correlated with more diverse posttreatment fecal microbiota. $^{211}$ Further developments of targeted bacteriotherapy ("synthetic microbial communities" or "microbial ecosystem therapeutics") may provide effective new approaches for CDI therapy. ${ }^{190,208,212}$

\section{Immunotherapy}

Low serum antibody levels against $C$. difficile toxins predispose patients to symptomatic ${ }^{39}$ and recurrent ${ }^{213,214} \mathrm{CDI}$. Intravenous immunoglobulin has been used for treatment of CDI, but the benefit is questionable. ${ }^{215}$ Monoclonal antibodies are a promising approach for treatment of CDI. ${ }^{216}$ In a Phase II double-blind RCT, the addition (to standard anti-CDI antibiotic therapy) of a single intravenous infusion of monoclonal antibodies against $C$. difficile toxins had no effect on initial cure rate but significantly reduced CDI recurrence (7 vs. $25 \%) .{ }^{217}$ Low serum antitoxin levels are associated with recurrence after therapy. ${ }^{217,218}$ The results of Phase III clinical trials near completion (ClinicalTrials.gov identifiers NCT01241552 and NCT01512239) are awaited with interest. Active immunization strategies aiming to provide long-term protection against $\mathrm{CDI}$ are also being developed. There are multiple candidate $C$. difficile vaccines in preclinical and clinical development. ${ }^{219,220}$

\section{References}

1 Young VB, Hanna PC. Overlapping roles for toxins in Clostridium difficile infection. J Infect Dis 2014;209(1):9-11

2 Lyras D, O'Connor JR, Howarth PM, et al. Toxin B is essential for virulence of Clostridium difficile. Nature 2009;458(7242): 1176-1179 
3 Kuehne SA, Cartman ST, Heap JT, Kelly ML, Cockayne A, Minton NP. The role of toxin A and toxin B in Clostridium difficile infection. Nature 2010;467(7316):711-713

4 Kuehne SA, Collery MM, Kelly ML, Cartman ST, Cockayne A, Minton NP. Importance of toxin A, toxin B, and CDT in virulence of an epidemic Clostridium difficile strain. J Infect Dis 2014; 209(1):83-86

5 Freeman J, Bauer MP, Baines SD, et al. The changing epidemiology of Clostridium difficile infections. Clin Microbiol Rev 2010;23(3): 529-549

6 Pépin J, Valiquette L, Alary M-E, et al. Clostridium difficileassociated diarrhea in a region of Quebec from 1991 to 2003: a changing pattern of disease severity. CMAJ 2004;171(5):466-472

7 Loo VG, Bourgault A-M, Poirier L, et al. Host and pathogen factors for Clostridium difficile infection and colonization. N Engl J Med 2011;365(18):1693-1703

8 McDonald LC, Killgore GE, Thompson A, et al. An epidemic, toxin gene-variant strain of Clostridium difficile. N Engl J Med 2005; 353(23):2433-2441

9 Warny M, Pepin J, Fang A, et al. Toxin production by an emerging strain of Clostridium difficile associated with outbreaks of severe disease in North America and Europe. Lancet 2005;366(9491): 1079-1084

10 Carter GP, Douce GR, Govind R, et al. The anti-sigma factor TcdC modulates hypervirulence in an epidemic BI/NAP1/027 clinical isolate of Clostridium difficile. PLoS Pathog 2011;7(10):e1002317

11 Magill SS, Edwards JR, Bamberg W, et al; Emerging Infections Program Healthcare-Associated Infections and Antimicrobial Use Prevalence Survey Team. Multistate point-prevalence survey of health care-associated infections. N Engl J Med 2014;370(13): 1198-1208

12 Miller BA, Chen LF, Sexton DJ, Anderson DJ. Comparison of the burdens of hospital-onset, healthcare facility-associated Clostridium difficile Infection and of healthcare-associated infection due to methicillin-resistant Staphylococcus aureus in community hospitals. Infect Control Hosp Epidemiol 2011;32(4):387-390

13 Centers for Disease Control and Prevention. Antibiotic resistance threats in the United States; 2013. Available at: http://www.cdc. gov/drugresistance/threat-report-2013/

14 Dubberke ER, Olsen MA. Burden of Clostridium difficile on the healthcare system. Clin Infect Dis 2012;55(Suppl 2):S88-S92

15 Hensgens MPM, Keessen EC, Squire MM, et al; European Society of Clinical Microbiology and Infectious Diseases Study Group for Clostridium difficile (ESGCD). Clostridium difficile infection in the community: a zoonotic disease? Clin Microbiol Infect 2012; 18(7):635-645

16 Khanna S, Pardi DS, Aronson SL, et al. The epidemiology of community-acquired Clostridium difficile infection: a population-based study. Am J Gastroenterol 2012;107(1):89-95

17 Khanna S, Pardi DS. Community-acquired Clostridium difficile infection: an emerging entity. Clin Infect Dis 2012;55(12): $1741-1742$

18 Lessa FC, Gould CV, McDonald LC. Current status of Clostridium difficile infection epidemiology. Clin Infect Dis 2012;55(Suppl 2): S65-S70

19 Lessa FC. Community-associated Clostridium difficile infection: how real is it? Anaerobe 2013;24:121-123

20 Slimings C, Riley TV. Antibiotics and hospital-acquired Clostridium difficile infection: update of systematic review and metaanalysis. J Antimicrob Chemother 2014;69(4):881-891

21 Brown KA, Khanafer N, Daneman N, Fisman DN. Meta-analysis of antibiotics and the risk of community-associated Clostridium difficile infection. Antimicrob Agents Chemother 2013;57(5): 2326-2332

22 Deshpande A, Pasupuleti V, Thota P, et al. Community-associated Clostridium difficile infection and antibiotics: a meta-analysis. J Antimicrob Chemother 2013;68(9):1951-1961
23 Britton RA, Young VB. Role of the intestinal microbiota in resistance to colonization by Clostridium difficile. Gastroenterology 2014;146(6):1547-1553

24 Hensgens MPM, Goorhuis A, Dekkers OM, Kuijper EJ. Time interval of increased risk for Clostridium difficile infection after exposure to antibiotics. J Antimicrob Chemother 2012;67(3): $742-748$

25 Janarthanan S, Ditah I, Adler DG, Ehrinpreis MN. Clostridium difficile-associated diarrhea and proton pump inhibitor therapy: a meta-analysis. Am J Gastroenterol 2012;107(7):1001-1010

26 Vonberg R-P, Kuijper EJ, Wilcox MH, et al; European C difficileInfection Control Group; European Centre for Disease Prevention and Control (ECDC). Infection control measures to limit the spread of Clostridium difficile. Clin Microbiol Infect 2008;14 (Suppl 5):2-20

27 Dubberke ER, Carling P, Carrico R, et al. Strategies to prevent Clostridium difficile infections in acute care hospitals: 2014 Update. Infect Control Hosp Epidemiol 2014;35(6):628-645

28 Edmonds SL, Zapka C, Kasper D, et al. Effectiveness of hand hygiene for removal of Clostridium difficile spores from hands. Infect Control Hosp Epidemiol 2013;34(3):302-305

29 McFarland LV, Mulligan ME, Kwok RY, Stamm WE. Nosocomial acquisition of Clostridium difficile infection. N Engl J Med 1989; 320(4):204-210

30 Weber DJ, Anderson DJ, Sexton DJ, Rutala WA. Role of the environment in the transmission of Clostridium difficile in health care facilities. Am J Infect Control 2013;41(5, Suppl):S105-S110

31 Wilcox MH, Fraise AP, Bradley CR, Walker J, Finch RG. Sporicides for Clostridium difficile: the devil is in the detail. J Hosp Infect 2011;77(3):187-188

32 Feazel LM, Malhotra A, Perencevich EN, Kaboli P, Diekema DJ, Schweizer ML. Effect of antibiotic stewardship programmes on Clostridium difficile incidence: a systematic review and metaanalysis. J Antimicrob Chemother 2014;69(7):1748-1754

33 Wilcox MH, Shetty N, Fawley WN, et al. Changing epidemiology of Clostridium difficile infection following the introduction of a national ribotyping-based surveillance scheme in England. Clin Infect Dis 2012;55(8):1056-1063

34 Debast SB, Bauer MP, Kuijper EJ; European Society of Clinical Microbiology and Infectious Diseases. European Society of Clinical Microbiology and Infectious Diseases: update of the treatment guidance document for Clostridium difficile infection. Clin Microbiol Infect 2014;20(Suppl 2):1-26

35 Bartlett JG. Clinical practice. Antibiotic-associated diarrhea. N Engl J Med 2002;346(5):334-339

36 Kelly CP, LaMont JT. Clostridium difficile-more difficult than ever. N Engl J Med 2008;359(18):1932-1940

37 Walker AS, Eyre DW, Wyllie DH, et al; Infections in Oxfordshire Research Database. Relationship between bacterial strain type, host biomarkers, and mortality in Clostridium difficile infection. Clin Infect Dis 2013;56(11):1589-1600

38 Aronoff DM. Editorial commentary: host-pathogen interactions in Clostridium difficile infection: it takes two to tango. Clin Infect Dis 2014;58(10):1401-1403

39 Kyne L, Warny M, Qamar A, Kelly CP. Asymptomatic carriage of Clostridium difficile and serum levels of IgG antibody against toxin A. N Engl J Med 2000;342(6):390-397

40 Alasmari F, Seiler SM, Hink T, Burnham C-AD, Dubberke ER. Prevalence and risk factors for asymptomatic Clostridium difficile carriage. Clin Infect Dis 2014;59(2):216-222

41 Riggs MM, Sethi AK, Zabarsky TF, Eckstein EC, Jump RLP, Donskey CJ. Asymptomatic carriers are a potential source for transmission of epidemic and nonepidemic Clostridium difficile strains among long-term care facility residents. Clin Infect Dis 2007;45(8): 992-998

42 Curry SR, Muto CA, Schlackman JL, et al. Use of multilocus variable number of tandem repeats analysis genotyping to determine the 
role of asymptomatic carriers in Clostridium difficile transmission. Clin Infect Dis 2013;57(8):1094-1102

43 Burnham C-AD, Carroll KC. Diagnosis of Clostridium difficile infection: an ongoing conundrum for clinicians and for clinical laboratories. Clin Microbiol Rev 2013;26(3):604-630

44 Crobach MJT, Dekkers OM, Wilcox MH, Kuijper EJ. European Society of Clinical Microbiology and Infectious Diseases (ESCMID): data review and recommendations for diagnosing Clostridium difficile-infection (CDI). Clin Microbiol Infect 2009; 15(12):1053-1066

45 Brecher SM, Novak-Weekley SM, Nagy E. Laboratory diagnosis of Clostridium difficile infections: there is light at the end of the colon. Clin Infect Dis 2013;57(8):1175-1181

46 Ticehurst JR, Aird DZ, Dam LM, Borek AP, Hargrove JT, Carroll KC. Effective detection of toxigenic Clostridium difficile by a two-step algorithm including tests for antigen and cytotoxin. J Clin Microbiol 2006;44(3):1145-1149

47 Aichinger E, Schleck CD, Harmsen WS, Nyre LM, Patel R. Nonutility of repeat laboratory testing for detection of Clostridium difficile by use of PCR or enzyme immunoassay. J Clin Microbiol 2008;46(11):3795-3797

48 Luo RF, Banaei N. Is repeat PCR needed for diagnosis of Clostridium difficile infection? J Clin Microbiol 2010;48(10):3738-3741

49 Cohen SH, Gerding DN, Johnson S, et al; Society for Healthcare Epidemiology of America; Infectious Diseases Society of America. Clinical practice guidelines for Clostridium difficile infection in adults: 2010 update by the society for healthcare epidemiology of America (SHEA) and the infectious diseases society of America (IDSA). Infect Control Hosp Epidemiol 2010;31(5):431-455

50 Planche T, Wilcox M. Reference assays for Clostridium difficile infection: one or two gold standards? J Clin Pathol 2011;64(1): $1-5$

51 Eastwood K, Else P, Charlett A, Wilcox M. Comparison of nine commercially available Clostridium difficile toxin detection assays, a real-time PCR assay for $C$. difficile $t c d B$, and a glutamate dehydrogenase detection assay to cytotoxin testing and cytotoxigenic culture methods. J Clin Microbiol 2009;47(10):3211-3217

52 Carroll KC. Tests for the diagnosis of Clostridium difficile infection: the next generation. Anaerobe 2011;17(4):170-174

53 Planche TD, Davies KA, Coen PG, et al. Differences in outcome according to Clostridium difficile testing method: a prospective multicentre diagnostic validation study of $C$ difficile infection. Lancet Infect Dis 2013;13(11):936-945

54 Goldenberg SD, Gumban M, Hall A, Patel A, French GL. Lack of effect of strain type on detection of toxigenic Clostridium difficile by glutamate dehydrogenase and polymerase chain reaction. Diagn Microbiol Infect Dis 2011;70(3):417-419

55 Carman RJ, Wickham KN, Chen L, et al. Glutamate dehydrogenase is highly conserved among Clostridium difficile ribotypes. J Clin Microbiol 2012;50(4):1425-1426

56 Shetty N, Wren MWD, Coen PG. The role of glutamate dehydrogenase for the detection of Clostridium difficile in faecal samples: a meta-analysis. J Hosp Infect 2011;77(1):1-6

57 Novak-Weekley SM, Marlowe EM, Miller JM, et al. Clostridium difficile testing in the clinical laboratory by use of multiple testing algorithms. J Clin Microbiol 2010;48(3):889-893

58 Kok J, Wang Q, Thomas LC, Gilbert GL. Presumptive identification of Clostridium difficile strain 027/NAP1/BI on Cepheid Xpert: interpret with caution. J Clin Microbiol 2011;49(10):3719-3721

59 Lim SK, Stuart RL, Mackin KE, et al. Emergence of a ribotype 244 strain of Clostridium difficile associated with severe disease and related to the epidemic ribotype 027 strain. Clin Infect Dis 2014; 58(12):1723-1730

60 Deshpande A, Pasupuleti V, Rolston DDK, et al. Diagnostic accuracy of real-time polymerase chain reaction in detection of Clostridium difficile in the stool samples of patients with suspected Clostridium difficile Infection: a meta-analysis. Clin Infect Dis 2011;53(7):e81-e90
61 Wilcox MH, Planche T, Fang FC, Gilligan P. What is the current role of algorithmic approaches for diagnosis of Clostridium difficile infection? J Clin Microbiol 2010;48(12):4347-4353

62 Surawicz CM, Brandt LJ, Binion DG, et al. Guidelines for diagnosis, treatment, and prevention of Clostridium difficile infections. Am J Gastroenterol 2013;108(4):478-498, quiz 499

63 Longtin Y, Trottier S, Brochu G, et al. Impact of the type of diagnostic assay on Clostridium difficile infection and complication rates in a mandatory reporting program. Clin Infect Dis 2013; 56(1):67-73

64 Goldenberg SD, Price NM, Tucker D, Wade P, French GL. Mandatory reporting and improvements in diagnosing Clostridium difficile infection: an incompatible dichotomy? J Infect 2011; 62(5):363-370

65 Gould CV, Edwards JR, Cohen J, et al; Clostridium difficile Infection Surveillance Investigators, Centers for Disease Control and Prevention. Effect of nucleic acid amplification testing on population-based incidence rates of Clostridium difficile infection. Clin Infect Dis 2013;57(9):1304-1307

66 Larson AM, Fung AM, Fang FC. Evaluation of tcdB real-time PCR in a three-step diagnostic algorithm for detection of toxigenic Clostridium difficile. J Clin Microbiol 2010;48(1):124-130

67 Babady NE, Stiles J, Ruggiero P, et al. Evaluation of the Cepheid Xpert Clostridium difficile Epi assay for diagnosis of Clostridium difficile infection and typing of the NAP1 strain at a cancer hospital. J Clin Microbiol 2010;48(12):4519-4524

68 Tedesco FJ. Antibiotic associated pseudomembranous colitis with negative proctosigmoidoscopy examination. Gastroenterology 1979;77(2):295-297

69 Tedesco FJ, Corless JK, Brownstein RE. Rectal sparing in antibioticassociated pseudomembranous colitis: a prospective study. Gastroenterology 1982;83(6):1259-1260

70 Johal SS, Hammond J, Solomon K, James PD, Mahida YR. Clostridium difficile associated diarrhoea in hospitalised patients: onset in the community and hospital and role of flexible sigmoidoscopy. Gut 2004;53(5):673-677

71 Fekety R, Shah AB. Diagnosis and treatment of Clostridium difficile colitis. JAMA 1993;269(1):71-75

72 Froberg MK, Palavecino E, Dykoski R, Gerding DN, Peterson LR, Johnson S. Staphylococcus aureus and Clostridium difficile cause distinct pseudomembranous intestinal diseases. Clin Infect Dis 2004;39(5):747-750

73 Price AB, Davies DR. Pseudomembranous colitis. J Clin Pathol 1977;30(1):1-12

74 Gerding DN, Olson MM, Peterson LR, et al. Clostridium difficileassociated diarrhea and colitis in adults. A prospective casecontrolled epidemiologic study. Arch Intern Med 1986;146(1): 95-100

75 Ananthakrishnan AN, Binion DG. Impact of Clostridium difficile on inflammatory bowel disease. Expert Rev Gastroenterol Hepatol 2010;4(5):589-600

76 Goodhand JR, Alazawi W, Rampton DS. Systematic review: Clostridium difficile and inflammatory bowel disease. Aliment Pharmacol Ther 2011;33(4):428-441

77 Kawamoto S, Horton KM, Fishman EK. Pseudomembranous colitis: spectrum of imaging findings with clinical and pathologic correlation. Radiographics 1999;19(4):887-897

78 Sheth SG, LaMont JT. Toxic megacolon. Lancet 1998;351(9101): 509-513

79 Valiquette L, Pépin J, Do X-V, et al. Prediction of complicated Clostridium difficile infection by pleural effusion and increased wall thickness on computed tomography. Clin Infect Dis 2009; 49(4):554-560

80 Boland GW, Lee MJ, Cats A, Mueller PR. Pseudomembranous colitis: diagnostic sensitivity of the abdominal plain radiograph. Clin Radiol 1994;49(7):473-475

81 Boland GW, Lee MJ, Cats AM, Gaa JA, Saini S, Mueller PR. Antibiotic-induced diarrhea: specificity of abdominal CT for the 
diagnosis of Clostridium difficile disease. Radiology 1994;191(1): 103-106

82 Ash L, Baker ME, O'Malley CM Jr, Gordon SM, Delaney CP, Obuchowski NA. Colonic abnormalities on CT in adult hospitalized patients with Clostridium difficile colitis: prevalence and significance of findings. AJR Am J Roentgenol 2006;186(5): 1393-1400

83 Kirkpatrick ID, Greenberg HM. Evaluating the CT diagnosis of Clostridium difficile colitis: should CT guide therapy? AJR Am J Roentgenol 2001;176(3):635-639

84 Garey KW, Sethi S, Yadav Y, DuPont HL. Meta-analysis to assess risk factors for recurrent Clostridium difficile infection. J Hosp Infect 2008;70(4):298-304

85 Mullane KM, Miller MA, Weiss K, et al. Efficacy of fidaxomicin versus vancomycin as therapy for Clostridium difficile infection in individuals taking concomitant antibiotics for other concurrent infections. Clin Infect Dis 2011;53(5):440-447 (Erratum in Clin Infect Dis. 2011;53(12):1312)

86 Teasley DG, Gerding DN, Olson MM, et al. Prospective randomised trial of metronidazole versus vancomycin for Clostridium-difficile-associated diarrhoea and colitis. Lancet 1983;2(8358): 1043-1046

87 Koo HL, Koo DC, Musher DM, DuPont HL. Antimotility agents for the treatment of Clostridium difficile diarrhea and colitis. Clin Infect Dis 2009;48(5):598-605

88 Chaparro-Rojas F, Mullane KM. Emerging therapies for Clostridium difficile infection-focus on fidaxomicin. Infect Drug Resist 2013;6:41-53

89 Gerding DN. Metronidazole for Clostridium difficile-associated disease: is it okay for Mom? Clin Infect Dis 2005;40(11): $1598-1600$

90 Drekonja DM, Butler M, MacDonald R, et al. Comparative effectiveness of Clostridium difficile treatments: a systematic review. Ann Intern Med 2011;155(12):839-847

91 Nelson RL, Kelsey P, Leeman H, et al. Antibiotic treatment for Clostridium difficile-associated diarrhea in adults. Cochrane Database Syst Rev 2011;(9):CD004610. doi: 10.1002/14651858. CD004610.pub4

92 Wilcox MH. Editorial Commentary: the trials and tribulations of treating Clostridium difficile infection-one step backward, one step forward, but still progress. Clin Infect Dis 2014;59(3): 355-357

93 Bartlett JG. The case for vancomycin as the preferred drug for treatment of Clostridium difficile infection. Clin Infect Dis 2008; 46(10):1489-1492

94 Tran M-CN, Claros MC, Goldstein EJC. Therapy of Clostridium difficile infection: perspectives on a changing paradigm. Expert Opin Pharmacother 2013;14(17):2375-2386

95 Musher DM, Aslam S, Logan N, et al. Relatively poor outcome after treatment of Clostridium difficile colitis with metronidazole. Clin Infect Dis 2005;40(11):1586-1590

96 Pepin J, Alary M-E, Valiquette L, et al. Increasing risk of relapse after treatment of Clostridium difficile colitis in Quebec, Canada. Clin Infect Dis 2005;40(11):1591-1597

97 Al-Nassir WN, Sethi AK, Nerandzic MM, Bobulsky GS, Jump RLP, Donskey CJ. Comparison of clinical and microbiological response to treatment of Clostridium difficile-associated disease with metronidazole and vancomycin. Clin Infect Dis 2008;47(1):56-62

98 Zar FA, Bakkanagari SR, Moorthi KMLST, Davis MB. A comparison of vancomycin and metronidazole for the treatment of Clostridium difficile-associated diarrhea, stratified by disease severity Clin Infect Dis 2007;45(3):302-307

99 Modena S, Gollamudi S, Friedenberg F. Continuation of antibiotics is associated with failure of metronidazole for Clostridium difficile-associated diarrhea. J Clin Gastroenterol 2006;40(1):49-54

100 Wilcox MH, Howe R. Diarrhoea caused by Clostridium difficile: response time for treatment with metronidazole and vancomycin. J Antimicrob Chemother 1995;36(4):673-679
101 Johnson S, Louie TJ, Gerding DN, et al; Polymer Alternative for CDI Treatment (PACT) investigators. Vancomycin, metronidazole, or tolevamer for Clostridium difficile infection: results from two multinational, randomized, controlled trials. Clin Infect Dis 2014; 59(3):345-354

102 Bolton RP, Culshaw MA. Faecal metronidazole concentrations during oral and intravenous therapy for antibiotic associated colitis due to Clostridium difficile. Gut 1986;27(10):1169-1172

103 Johnson S, Homann SR, Bettin KM, et al. Treatment of asymptomatic Clostridium difficile carriers (fecal excretors) with vancomycin or metronidazole. A randomized, placebo-controlled trial. Ann Intern Med 1992;117(4):297-302

104 Baines SD, O'Connor R, Freeman J, et al. Emergence of reduced susceptibility to metronidazole in Clostridium difficile. J Antimicrob Chemother 2008;62(5):1046-1052

105 Hecht DW, Galang MA, Sambol SP, Osmolski JR, Johnson S, Gerding DN. In vitro activities of 15 antimicrobial agents against 110 toxigenic clostridium difficile clinical isolates collected from 1983 to 2004. Antimicrob Agents Chemother 2007;51(8): 2716-2719

106 Sears P, Crook DW, Louie TJ, Miller MA, Weiss K. Fidaxomicin attains high fecal concentrations with minimal plasma concentrations following oral administration in patients with Clostridium difficile infection. Clin Infect Dis 2012;55(Suppl 2): S116-S120

107 Weiss K, Allgren RL, Sellers S. Safety analysis of fidaxomicin in comparison with oral vancomycin for Clostridium difficile infections. Clin Infect Dis 2012;55(Suppl 2):S110-S115

108 Louie TJ, Miller MA, Mullane KM, et al; OPT-80-003 Clinical Study Group. Fidaxomicin versus vancomycin for Clostridium difficile infection. N Engl J Med 2011;364(5):422-431

109 Cornely OA, Crook DW, Esposito R, et al; OPT-80-004 Clinical Study Group. Fidaxomicin versus vancomycin for infection with Clostridium difficile in Europe, Canada, and the USA: a doubleblind, non-inferiority, randomised controlled trial. Lancet Infect Dis 2012;12(4):281-289

110 Cornely OA, Nathwani D, Ivanescu C, Odufowora-Sita O, Retsa P, Odeyemi IAO. Clinical efficacy of fidaxomicin compared with vancomycin and metronidazole in Clostridium difficile infections: a meta-analysis and indirect treatment comparison. J Antimicrob Chemother 2014;69(11):2892-2900

111 Petrella LA, Sambol SP, Cheknis A, et al. Decreased cure and increased recurrence rates for Clostridium difficile infection caused by the epidemic C. difficile BI strain. Clin Infect Dis 2012;55(3):351-357

112 Babakhani F, Bouillaut L, Sears P, Sims C, Gomez A, Sonenshein AL Fidaxomicin inhibits toxin production in Clostridium difficile. J Antimicrob Chemother 2013;68(3):515-522

113 Babakhani F, Bouillaut L, Gomez A, Sears P, Nguyen L, Sonenshein AL. Fidaxomicin inhibits spore production in Clostridium difficile. Clin Infect Dis 2012;55(Suppl 2):S162-S169

114 Tannock GW, Munro K, Taylor C, et al. A new macrocyclic antibiotic, fidaxomicin (OPT-80), causes less alteration to the bowel microbiota of Clostridium difficile-infected patients than does vancomycin. Microbiology 2010;156(Pt 11):3354-3359

115 Louie TJ, Cannon K, Byrne B, et al. Fidaxomicin preserves the intestinal microbiome during and after treatment of Clostridium difficile infection (CDI) and reduces both toxin reexpression and recurrence of CDI. Clin Infect Dis 2012;55(Suppl 2): S132-S142

116 Louie TJ, Emery J, Krulicki W, Byrne B, Mah M. OPT-80 eliminates Clostridium difficile and is sparing of bacteroides species during treatment of $C$. difficile infection. Antimicrob Agents Chemother 2009;53(1):261-263

117 Eyre DW, Babakhani F, Griffiths D, et al. Whole-genome sequencing demonstrates that fidaxomicin is superior to vancomycin for preventing reinfection and relapse of infection with Clostridium difficile. J Infect Dis 2014;209(9):1446-1451 
118 Nerandzic MM, Mullane K, Miller MA, Babakhani F, Donskey CJ. Reduced acquisition and overgrowth of vancomycin-resistant enterococci and Candida species in patients treated with fidaxomicin versus vancomycin for Clostridium difficile infection. Clin Infect Dis 2012;55(Suppl 2):S121-S126

119 Bartsch SM, Umscheid CA, Fishman N, Lee BY. Is fidaxomicin worth the cost? An economic analysis. Clin Infect Dis 2013;57(4): 555-561

120 Nathwani D, Cornely OA, Van Engen AK, Odufowora-Sita O, Retsa P, Odeyemi IAO. Cost-effectiveness analysis of fidaxomicin versus vancomycin in Clostridium difficile infection. J Antimicrob Chemother 2014;69(11):2901-2912

121 Musher DM, Logan N, Bressler AM, Johnson DP, Rossignol JF. Nitazoxanide versus vancomycin in Clostridium difficile infection: a randomized, double-blind study. Clin Infect Dis 2009; 48(4):e41-e46

122 Zucca M, Scutera S, Savoia D. Novel avenues for Clostridium difficile infection drug discovery. Expert Opin Drug Discov 2013;8(4):459-477

123 Abou Chakra CN, Pepin J, Sirard S, Valiquette L. Risk factors for recurrence, complications and mortality in Clostridium difficile infection: a systematic review. PLoS ONE 2014;9(6):e98400

124 Bauer MP, Hensgens MPM, Miller MA, et al. Renal failure and leukocytosis are predictors of a complicated course of Clostridium difficile infection if measured on day of diagnosis. Clin Infect Dis 2012;55(Suppl 2):S149-S153

125 Miller MA, Louie T, Mullane K, et al. Derivation and validation of a simple clinical bedside score (ATLAS) for Clostridium difficile infection which predicts response to therapy. BMC Infect Dis 2013;13:148

126 Abou Chakra CN, Pepin J, Valiquette L. Prediction tools for unfavourable outcomes in Clostridium difficile infection: a systematic review. PLoS ONE 2012;7(1):e30258

127 Goorhuis A, Bakker D, Corver J, et al. Emergence of Clostridium difficile infection due to a new hypervirulent strain, polymerase chain reaction ribotype 078. Clin Infect Dis 2008;47(9): $1162-1170$

128 Miller M, Gravel D, Mulvey M, et al. Health care-associated Clostridium difficile infection in Canada: patient age and infecting strain type are highly predictive of severe outcome and mortality. Clin Infect Dis 2010;50(2):194-201

129 Gerding DN, Johnson S. Does infection with specific Clostridium difficile strains or clades influence clinical outcome? Clin Infect Dis 2013;56(11):1601-1603

130 Walk ST, Micic D, Galecki AT, Young VB, Aronoff DM. Understanding increased mortality in Clostridium difficile-infected older adults. Clin Infect Dis 2013;57(4):625-626

131 See I, Mu Y, Cohen J, et al. NAP1 strain type predicts outcomes from Clostridium difficile infection. Clin Infect Dis 2014;58(10): 1394-1400

132 Johnson S. Editorial commentary: changing epidemiology of Clostridium difficile and emergence of new virulent strains. Clin Infect Dis 2014;58(12):1731-1733

133 Fekety R, Silva J, Kauffman C, Buggy B, Deery HG. Treatment of antibiotic-associated Clostridium difficile colitis with oral vancomycin: comparison of two dosage regimens. Am J Med 1989; 86(1):15-19

134 Friedenberg F, Fernandez A, Kaul V, Niami P, Levine GM. Intravenous metronidazole for the treatment of Clostridium difficile colitis. Dis Colon Rectum 2001;44(8):1176-1180

135 Bass SN, Bauer SR, Neuner EA, Lam SW. Comparison of treatment outcomes with vancomycin alone versus combination therapy in severe Clostridium difficile infection. J Hosp Infect 2013;85(1): 22-27

136 Wenisch JM, Schmid D, Kuo H-W, et al. Prospective observational study comparing three different treatment regimes in patients with Clostridium difficile infection. Antimicrob Agents Chemother 2012;56(4):1974-1978
137 Tedesco F, Markham R, Gurwith M, Christie D, Bartlett JG. Oral vancomycin for antibiotic-associated pseudomembranous colitis. Lancet 1978;2(8083):226-228

138 Aldape MJ, Heeney DD, Bryant AE, Stevens DL. Tigecycline suppresses toxin A and B production and sporulation in Clostridium difficile. J Antimicrob Chemother 2015;70:153-159

139 Nord CE, Sillerström E, Wahlund E. Effect of tigecycline on normal oropharyngeal and intestinal microflora. Antimicrob Agents Chemother 2006;50(10):3375-3380

140 Jump RLP, Li Y, Pultz MJ, Kypriotakis G, Donskey CJ. Tigecycline exhibits inhibitory activity against Clostridium difficile in the colon of mice and does not promote growth or toxin production. Antimicrob Agents Chemother 2011;55(2):546-549

141 Herpers BL, Vlaminckx B, Burkhardt O, et al. Intravenous tigecycline as adjunctive or alternative therapy for severe refractory Clostridium difficile infection. Clin Infect Dis 2009;48(12): 1732-1735

142 Thomas A, Khan F, Uddin N, Wallace MR. Tigecycline for severe Clostridium difficile infection. Int J Infect Dis 2014;26:171-172

143 Cheong EYL, Gottlieb T. Intravenous tigecycline in the treatment of severe recurrent Clostridium difficile colitis. Med J Aust 2011; 194(7):374-375

144 Apisarnthanarak A, Razavi B, Mundy LM. Adjunctive intracolonic vancomycin for severe Clostridium difficile colitis: case series and review of the literature. Clin Infect Dis 2002;35(6):690-696

$145 \mathrm{Kim}$ PK, Huh HC, Cohen HW, et al. Intracolonic vancomycin for severe Clostridium difficile colitis. Surg Infect (Larchmt) 2013; 14(6):532-539

146 Saffouri G, Khanna S, Estes L, Pardi D. Outcomes from rectal vancomycin therapy in patients with Clostridium difficile infection. Am J Gastroenterol 2014;109(6):924-925

147 Bhangu A, Nepogodiev D, Gupta A, Torrance A, Singh P; West Midlands Research Collaborative. Systematic review and metaanalysis of outcomes following emergency surgery for Clostridium difficile colitis. Br J Surg 2012;99(11):1501-1513

148 Lamontagne F, Labbé A-C, Haeck O, et al. Impact of emergency colectomy on survival of patients with fulminant Clostridium difficile colitis during an epidemic caused by a hypervirulent strain. Ann Surg 2007;245(2):267-272

149 Stewart DB, Hollenbeak CS, Wilson MZ. Is colectomy for fulminant Clostridium difficile colitis life saving? A systematic review. Colorectal Dis 2013;15(7):798-804

150 Noblett SE, Welfare M, Seymour K. The role of surgery in Clostridium difficile colitis. BMJ 2009;338:b1563

151 Karmali S, Laffin M, de Gara C. CAGS Clinical Practice Committee report: the science of Clostridium difficile and surgery. Can J Surg 2013;56(6):367-371

152 Ferrada P, Velopulos CG, Sultan S, et al. Timing and type of surgical treatment of Clostridium difficile-associated disease: a practice management guideline from the Eastern Association for the Surgery of Trauma. J Trauma Acute Care Surg 2014;76(6): 1484-1493

153 Sailhamer EA, Carson K, Chang Y, et al. Fulminant Clostridium difficile colitis: patterns of care and predictors of mortality. Arch Surg 2009;144(5):433-439, discussion 439-440

154 Neal MD, Alverdy JC, Hall DE, Simmons RL, Zuckerbraun BS. Diverting loop ileostomy and colonic lavage: an alternative to total abdominal colectomy for the treatment of severe, complicated Clostridium difficile associated disease. Ann Surg 2011; 254(3):423-427, discussion 427-429

155 Brown CJ, Boutros M, Morris A, Divino CM; CAGS/ACS Evidence Based Reviews in Surgery Group. CAGS and ACS evidence based reviews in surgery. Is a diverting loop ileostomy and colonic lavage an alternative to colectomy for the treatment of severe Clostridium difficile-associated disease? Can J Surg 2014;57(3): 214-216

156 McFarland LV, Surawicz CM, Greenberg RN, et al. A randomized placebo-controlled trial of Saccharomyces boulardii in 
combination with standard antibiotics for Clostridium difficile disease. JAMA 1994;271(24):1913-1918

157 McFarland LV, Elmer GW, Surawicz CM. Breaking the cycle: treatment strategies for 163 cases of recurrent Clostridium difficile disease. Am J Gastroenterol 2002;97(7):1769-1775

158 Cornely OA, Miller MA, Louie TJ, Crook DW, Gorbach SL. Treatment of first recurrence of Clostridium difficile infection: fidaxomicin versus vancomycin. Clin Infect Dis 2012;55(Suppl 2): S154-S161

159 Tedesco FJ, Gordon D, Fortson WC. Approach to patients with multiple relapses of antibiotic-associated pseudomembranous colitis. Am J Gastroenterol 1985;80(11):867-868

160 Johnson S, Gerding DN. Fidaxomicin "chaser" regimen following vancomycin for patients with multiple Clostridium difficile recurrences. Clin Infect Dis 2013;56(2):309-310

161 Ojaimi S, Korman TM. Rifaximin. In: Grayson M, Crowe S, McCarthy J, et al, eds. Kucers' the Use of Antibiotics: American Society for Microbiology and Hodder Arnold; 2010

162 Johnson S, Schriever C, Galang M, Kelly CP, Gerding DN. Interruption of recurrent Clostridium difficile-associated diarrhea episodes by serial therapy with vancomycin and rifaximin. Clin Infect Dis 2007;44(6):846-848

163 Garey KW, Jiang ZD, Bellard A, Dupont HL. Rifaximin in treatment of recurrent Clostridium difficile-associated diarrhea: an uncontrolled pilot study. J Clin Gastroenterol 2009;43(1):91-93

164 Rubin DT, Sohi S, Glathar M, Thomas T, Yadron N, Surma BL. Rifaximin is effective for the treatment of Clostridium difficileassociated diarrhea: results of an open-label pilot study. Gastroenterol Res Pract 2011;2011:106978

165 Mattila E, Arkkila P, Mattila PS, Tarkka E, Tissari P, Anttila V-J. Rifaximin in the treatment of recurrent Clostridium difficile infection. Aliment Pharmacol Ther 2013;37(1):122-128

166 Garey KW, Ghantoji SS, Shah DN, et al. A randomized, doubleblind, placebo-controlled pilot study to assess the ability of rifaximin to prevent recurrent diarrhoea in patients with Clostridium difficile infection. J Antimicrob Chemother 2011;66(12): 2850-2855

167 O'Connor JR, Galang MA, Sambol SP, et al. Rifampin and rifaximin resistance in clinical isolates of Clostridium difficile. Antimicrob Agents Chemother 2008;52(8):2813-2817

168 Curry SR, Marsh JW, Shutt KA, et al. High frequency of rifampin resistance identified in an epidemic Clostridium difficile clone from a large teaching hospital. Clin Infect Dis 2009;48(4): 425-429

169 Huang JS, Jiang ZD, Garey KW, Lasco T, Dupont HL. Use of rifamycin drugs and development of infection by rifamycinresistant strains of Clostridium difficile. Antimicrob Agents Chemother 2013;57(6):2690-2693

170 Miller MA, Blanchette R, Spigaglia P, Barbanti F, Mastrantonio P. Divergent rifamycin susceptibilities of Clostridium difficile strains in Canada and Italy and predictive accuracy of rifampin Etest for rifamycin resistance. J Clin Microbiol 2011;49(12):4319-4321

171 Schubert AM, Rogers MAM, Ring C, et al. Microbiome data distinguish patients with Clostridium difficile infection and non-C. difficile-associated diarrhea from healthy controls. MBio 2014;5(3):e01021-e14

172 Chang JY, Antonopoulos DA, Kalra A, et al. Decreased diversity of the fecal Microbiome in recurrent Clostridium difficile-associated diarrhea. J Infect Dis 2008;197(3):435-438

173 Martin J, Mawer D, Wilcox MH. Clostridium difficile: biological therapies. Curr Opin Infect Dis 2013;26(5):454-460

174 Shim JK, Johnson S, Samore MH, Bliss DZ, Gerding DN. Primary symptomless colonisation by Clostridium difficile and decreased risk of subsequent diarrhoea. Lancet 1998;351(9103):633-636

175 Seal D, Borriello SP, Barclay F, Welch A, Piper M, Bonnycastle M. Treatment of relapsing Clostridium difficile diarrhoea by administration of a non-toxigenic strain. Eur J Clin Microbiol 1987;6(1): $51-53$
176 Villano SA, Seiberling M, Tatarowicz W, Monnot-Chase E, Gerding DN. Evaluation of an oral suspension of VP20621, spores of nontoxigenic Clostridium difficile strain M3, in healthy subjects. Antimicrob Agents Chemother 2012;56(10):5224-5229

177 Villano SA, Armstrong J, Meyer T, et al. Therapeutic Use of an Oral Suspension of VP20621, Spores of a Non-Toxigenic Clostridium difficile (NTCD) Strain, for Prevention of Recurrence of C. difficile Infection (CDI). ID Week 2013. Late Breaker Oral Abstracts LB-7. September 28, 2013:169b

178 Miller M. The fascination with probiotics for Clostridium difficile infection: lack of evidence for prophylactic or therapeutic efficacy. Anaerobe 2009;15(6):281-284

179 Tasteyre A, Barc M-C, Karjalainen T, Bourlioux P, Collignon A. Inhibition of in vitro cell adherence of Clostridium difficile by Saccharomyces boulardii. Microb Pathog 2002;32(5):219-225

180 Castagliuolo I, Riegler MF, Valenick L, LaMont JT, Pothoulakis C. Saccharomyces boulardii protease inhibits the effects of Clostridium difficile toxins $A$ and $B$ in human colonic mucosa. Infect Immun 1999;67(1):302-307

181 Chen X, Kokkotou EG, Mustafa N, et al. Saccharomyces boulardii inhibits ERK1/2 mitogen-activated protein kinase activation both in vitro and in vivo and protects against Clostridium difficile toxin A-induced enteritis. J Biol Chem 2006;281(34):24449-24454

182 Qamar A, Aboudola S, Warny M, et al. Saccharomyces boulardii stimulates intestinal immunoglobulin A immune response to Clostridium difficile toxin A in mice. Infect Immun 2001;69(4): 2762-2765

183 Pillai A, Nelson R. Probiotics for treatment of Clostridium difficileassociated colitis in adults. Cochrane Database Syst Rev 2008; 1(1):CD004611

184 Goldenberg JZ, Ma SS, Saxton JD, et al. Probiotics for the prevention of Clostridium difficile-associated diarrhea in adults and children. Cochrane Database Syst Rev 2013;5:CD006095

185 Johnston BC, Ma SSY, Goldenberg JZ, et al. Probiotics for the prevention of Clostridium difficile-associated diarrhea: a systematic review and meta-analysis. Ann Intern Med 2012;157(12): 878-888

186 Allen SJ, Wareham K, Bradley C, et al. A multicentre randomised controlled trial evaluating lactobacilli and bifidobacteria in the prevention of antibiotic-associated diarrhoea in older people admitted to hospital: the PLACIDE study protocol. BMC Infect Dis 2012;12:108

187 Allen SJ, Wareham K, Wang D, et al. Lactobacilli and bifidobacteria in the prevention of antibiotic-associated diarrhoea and Clostridium difficile diarrhoea in older inpatients (PLACIDE): a randomised, double-blind, placebo-controlled, multicentre trial. Lancet 2013;382(9900):1249-1257

188 Brandt LJ. American Journal of Gastroenterology Lecture: Intestinal microbiota and the role of fecal microbiota transplant (FMT) in treatment of C. difficile infection. Am J Gastroenterol 2013; 108(2):177-185

189 Khoruts A, Dicksved J, Jansson JK, Sadowsky MJ. Changes in the composition of the human fecal microbiome after bacteriotherapy for recurrent Clostridium difficile-associated diarrhea. J Clin Gastroenterol 2010;44(5):354-360

190 Petrof EO, Khoruts A. From stool transplants to next-generation microbiota therapeutics. Gastroenterology 2014;146(6): 1573-1582

191 Brandt LJ, Reddy SS. Fecal microbiota transplantation for recurrent clostridium difficile infection. J Clin Gastroenterol 2011;45 (Suppl):S159-S167

192 van Nood E, Speelman P, Kuijper EJ, Keller JJ. Struggling with recurrent Clostridium difficile infections: is donor faeces the solution? Euro Surveill 2009;14(34):1-6

193 Gough E, Shaikh H, Manges AR. Systematic review of intestinal microbiota transplantation (fecal bacteriotherapy) for recurrent Clostridium difficile infection. Clin Infect Dis 2011;53(10): 994-1002 
194 Kassam Z, Lee CH, Yuan Y, Hunt RH. Fecal microbiota transplantation for Clostridium difficile infection: systematic review and meta-analysis. Am J Gastroenterol 2013;108(4):500-508

195 Guo B, Harstall C, Louie T, Veldhuyzen van Zanten S, Dieleman LA. Systematic review: faecal transplantation for the treatment of Clostridium difficile-associated disease. Aliment Pharmacol Ther 2012;35(8):865-875

196 Sofi AA, Silverman AL, Khuder S, Garborg K, Westerink JMA, Nawras A. Relationship of symptom duration and fecal bacteriotherapy in Clostridium difficile infection-pooled data analysis and a systematic review. Scand J Gastroenterol 2013;48(3):266-273

197 van Nood E, Vrieze A, Nieuwdorp M, et al. Duodenal infusion of donor feces for recurrent Clostridium difficile. N Engl J Med 2013; 368(5):407-415

198 Brandt LJ, Borody TJ, Campbell J. Endoscopic fecal microbiota transplantation: "first-line" treatment for severe clostridium difficile infection? J Clin Gastroenterol 2011;45(8):655-657

199 Trubiano JA, Gardiner B, Kwong JC, Ward P, Testro AG, Charles PGP. Faecal microbiota transplantation for severe Clostridium difficile infection in the intensive care unit. Eur J Gastroenterol Hepatol 2013;25(2):255-257

200 Kelly CR, Ihunnah C, Fischer M, et al. Fecal microbiota transplant for treatment of Clostridium difficile infection in immunocompromised patients. Am J Gastroenterol 2014;109(7):1065-1071

201 Konijeti GG, Sauk J, Shrime MG, Gupta M, Ananthakrishnan AN. Cost-effectiveness of competing strategies for management of recurrent Clostridium difficile infection: a decision analysis. Clin Infect Dis 2014;58(11):1507-1514

202 Food and Drug Administration. Guidance for Industry: Enforcement Policy Regarding Investigational New Drug Requirements for Use of Fecal Microbiota for Transplantation to Treat Clostridium difficile Infection Not Responsive to Standard Therapies. July 2013. Available at: http://www.fda.gov/BiologicsBloodVaccines/GuidanceComplianceRegulatoryInformation/Guidances/ Vaccines/ucm361379.htm

203 Hecht GA, Blaser MJ, Gordon J, et al. What is the value of a food and drug administration investigational new drug application for fecal microbiota transplantation to treat Clostridium difficile Infection? Clin Gastroenterol Hepatol 2014;12(2):289-291

204 Bakken JS, Borody T, Brandt LJ, et al; Fecal Microbiota Transplantation Workgroup. Treating Clostridium difficile infection with fecal microbiota transplantation. Clin Gastroenterol Hepatol 2011;9(12):1044-1049

205 Hamilton MJ, Weingarden AR, Sadowsky MJ, Khoruts A. Standardized frozen preparation for transplantation of fecal microbiota for recurrent Clostridium difficile infection. Am J Gastroenterol 2012;107(5):761-767
206 Youngster I, Sauk J, Pindar C, et al. Fecal microbiota transplant for relapsing Clostridium difficile infection using a frozen inoculum from unrelated donors: a randomized, open-label, controlled pilot study. Clin Infect Dis 2014;58(11):1515-1522

207 Adamu BO, Lawley TD. Bacteriotherapy for the treatment of intestinal dysbiosis caused by Clostridium difficile infection. Curr Opin Microbiol 2013;16(5):596-601

208 de Vos WM. Fame and future of faecal transplantations-developing next-generation therapies with synthetic microbiomes. Microb Biotechnol 2013;6(4):316-325

209 Tvede M, Rask-Madsen J. Bacteriotherapy for chronic relapsing Clostridium difficile diarrhoea in six patients. Lancet 1989; 1(8648): 1156-1160

210 Lawley TD, Clare S, Walker AW, et al. Targeted restoration of the intestinal microbiota with a simple, defined bacteriotherapy resolves relapsing Clostridium difficile disease in mice. PLoS Pathog 2012;8(10):e1002995

211 Petrof EO, Gloor GB, Vanner SJ, et al. Stool substitute transplant therapy for the eradication of Clostridium difficile infection: 'RePOOPulating' the gut. Microbiome 2013;1(1):3

212 Allen-Vercoe E, Petrof EO. Artificial stool transplantation: progress towards a safer, more effective and acceptable alternative. Expert Rev Gastroenterol Hepatol 2013;7(4):291-293

213 Kyne L, Warny M, Qamar A, Kelly CP. Association between antibody response to toxin A and protection against recurrent Clostridium difficile diarrhoea. Lancet 2001;357(9251):189-193

214 Bauer MP, Nibbering PH, Poxton IR, Kuijper EJ, van Dissel JT. Humoral immune response as predictor of recurrence in Clostridium difficile infection. Clin Microbiol Infect 2014

215 Abougergi MS, Broor A, Cui W, Jaar BG. Intravenous immunoglobulin for the treatment of severe Clostridium difficile colitis: an observational study and review of the literature. J Hosp Med 2010;5(1):E1-E9

216 Humphreys DP, Wilcox MH. Antibodies for treatment of Clostridium difficile infection. Clin Vaccine Immunol 2014;21(7):913-923

217 Lowy I, Molrine DC, Leav BA, et al. Treatment with monoclonal antibodies against Clostridium difficile toxins. N Engl J Med 2010; 362(3):197-205

218 Leav BA, Blair B, Leney M, et al. Serum anti-toxin B antibody correlates with protection from recurrent Clostridium difficile infection (CDI). Vaccine 2010;28(4):965-969

219 Lee BY, Popovich MJ, Tian Y, et al. The potential value of Clostridium difficile vaccine: an economic computer simulation model. Vaccine 2010;28(32):5245-5253

220 Mizrahi A, Collignon A, Péchiné S. Passive and active immunization strategies against Clostridium difficile infections: State of the art. Anaerobe 2014 